\title{
Neonatal Leptin Exposure Specifies Innervation of Presympathetic Hypothalamic Neurons and Improves the Metabolic Status of Leptin-Deficient Mice
}

\author{
Karine Bouyer and Richard B. Simerly \\ Neuroscience Program, The Saban Research Institute, Children's Hospital Los Angeles, University of Southern California, Keck School of Medicine, Los \\ Angeles, California 90027
}

\begin{abstract}
The paraventricular nucleus of the hypothalamus $(\mathrm{PVH})$ consists of distinct functional compartments regulating neuroendocrine, behavioral, and autonomic activities that are involved in the homeostatic control of energy balance. These compartments receive synaptic inputs from neurons of the arcuate nucleus of the hypothalamus (ARH) that contains orexigenic agouti-related peptide (AgRP) and anorexigenic pro-opiomelanocortin (POMC) neuropeptides. The axon outgrowth from the ARH to PVH occurs during a critical postnatal period and is influenced by the adipocyte-derived hormone leptin, which promotes its development. However, little is known about leptin's role in specifying patterns of cellular connectivity in the different compartments of the PVH. To address this question, we used retrograde and immunohistochemical labeling to evaluate neuronal inputs onto sympathetic preautonomic and neuroendocrine neurons in PVH of leptin-deficient mice (Lep ${ }^{\mathrm{ob}} / \mathrm{Lep}^{\mathrm{ob}}$ ) exposed to a postnatal leptin treatment. In adult Lep ${ }^{\mathrm{ob}} / \mathrm{Lep}^{\mathrm{ob}}$ mice, densities of AgRPand $\alpha$-melanocortin stimulating hormone ( $\alpha \mathrm{MSH})$-immunoreactive fibers were significantly reduced in neuroendocrine compartments of the PVH, but only AgRP were reduced in all regions containing preautonomic neurons. Moreover, postnatal leptin treatment significantly increased the density of AgRP-containing fibers and peptidergic inputs onto identified preautonomic, but not onto neuroendocrine cells. Neonatal leptin treatment neither rescued $\alpha \mathrm{MSH}$ inputs onto neuroendocrine neurons, nor altered cellular ratios of inhibitory and excitatory inputs. These effects were associated with attenuated body weight gain, food intake and improved physiological response to sympathetic stimuli. Together, these results provide evidence that leptin directs cell type-specific patterns of ARH peptidergic inputs onto preautonomic neurons in the $\mathrm{PVH}$, which contribute to normal energy balance regulation.
\end{abstract}

\section{Introduction}

The hypothalamus is distinct in its ability to integrate humoral signals with sensory information from the environment and translate it into metabolic output through the control of neuroendocrine secretions or autonomic responses. The paraventricular nucleus of the hypothalamus (PVH) has long been recognized as a key site for such integration because of its highly organized structure consisting of functionally relevant subcompartments (Biag et al., 2012). Whereas its magnocellular and medial parvocellular parts are involved in the control of hormone secretion from the anterior pituitary, the lateral parvocellular part innervates regions of the brainstem and spinal cord that

Received July 5, 2012; revised 0ct. 21, 2012; accepted Nov. 9, 2012.

Author contributions: K.B. and R.B.S. designed research; K.B. performed research; K.B. contributed unpublished reagents/analytic tools; K.B. and R.B.S. analyzed data; K.B. and R.B.S. wrote the paper.

This work was supported by National Institutes of Health Grants DK065900 and DK057768 to (R.B.S.), and the French Foundation for Medical Research (postdoctoral fellowship to K.B.). We thank Dr. H.-W. Dong (LONI, Department of Neurology, UCLA School of Medicine) for invaluable advice on surgical procedures, anatomical definitions, and for kindly providing us with the PVH schematic used in this manuscript.

The authors declare no competing financial interests.

Correspondence should be addressed to Richard B. Simerly, Neuroscience Program, The Saban Research Institute, Children's Hospital Los Angeles, University of Southern California, 4650 Sunset Boulevard, MS\#135, Los Angeles, CA 90027. E-mail: rsimerly@usc.edu.

DOI:10.1523/JNEUROSCI.3215-12.2013

Copyright $\odot 2013$ the authors $\quad 0270-6474 / 13 / 330840-12 \$ 15.00 / 0$ regulate the activity of autonomic neurons and provides inputs to several midbrain regions involved in coordination of a variety of goal-oriented behaviors (Swanson, 2000). In this way, information about current metabolic state is integrated, such that counter-regulatory, endocrine, autonomic, and behavioral responses are coordinated to maintain energy balance.

The arcuate nucleus of the hypothalamus (ARH) innervates a number of regions involved in regulating energy balance, and two populations of peptidergic neurons provide convergent inputs to neuroendocrine and preautonomic PVH neurons (Elias et al., 1998; Fekete et al., 2000). Orexigenic neuropeptide-Y (NPY) neurons, which coexpress agouti-related peptide (AgRP), and anorexigenic POMC neurons, which produce melanocortin peptides including $\alpha$-melanocortin stimulating hormone $(\alpha \mathrm{MSH})$, play important roles in regulating food intake and glucose metabolism (Coppari et al., 2005). The adipocyte-derived hormone leptin represents a key peripheral signal that is required to maintain normal body weight. Moreover, it acts directly on NPY and POMC neurons with opposing effects on neuronal activity and gene expression to regulate energy balance (Schwartz et al., 2000; Cowley et al., 2001; van den Top et al., 2004).

In addition to its regulatory role in mature animals, leptin functions as a developmental signal during formation of ARH connectivity (Simerly, 2008). ARH projections to the PVH develop primarily between the fourth and 14th postnatal day, and 


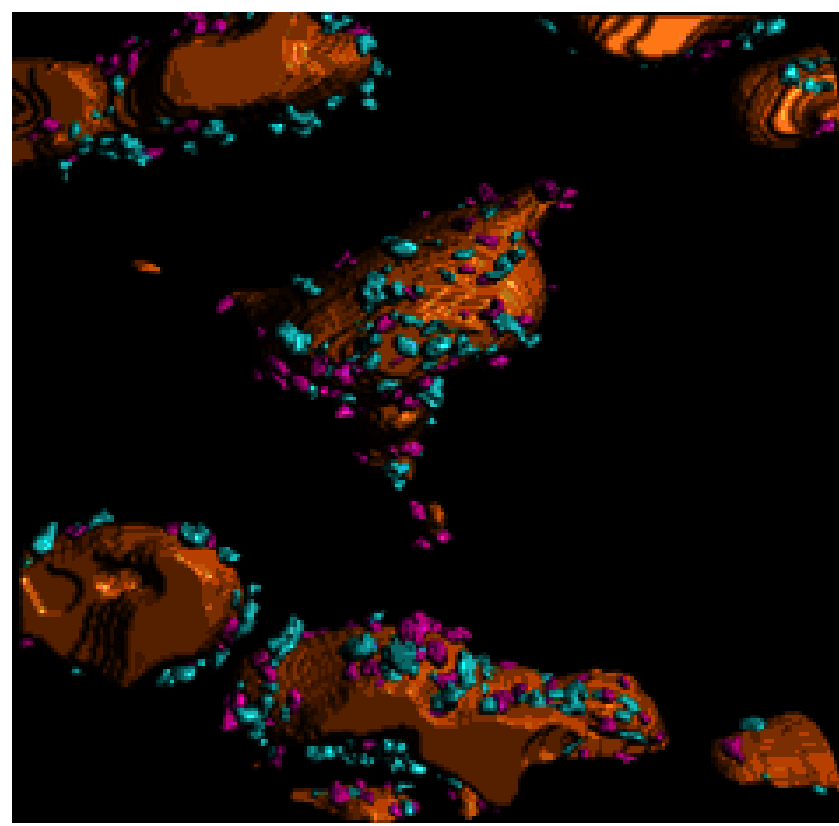

Movie 1. Video of three-dimensional visualization of neuronal inputs onto identified PVH neurons. Rotating rendering of a 4-channel image stack illustrating the visualization and quantification protocol used to measure the density of neuronal inputs onto identified PVH neurons. By using Volocity image analysis software, each putative presynaptic excitatory (vGlut2, red channel) or inhibitory (VGAT, green channel) input was defined as a three-dimensional object in direct contact with the postsynaptic target neuron (magenta and cyan, respectively). The limits of the postsynaptic neuron were defined with HuC/D immunostaining (blue channel) and preautonomic neurons represent a subset of these cells that contained the retrograde tracer Fluorogold (orange channel). IML, Intermediolateral column.
A

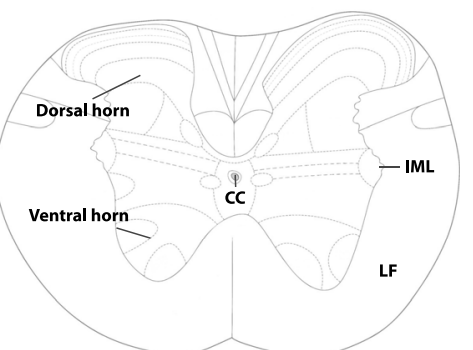

B

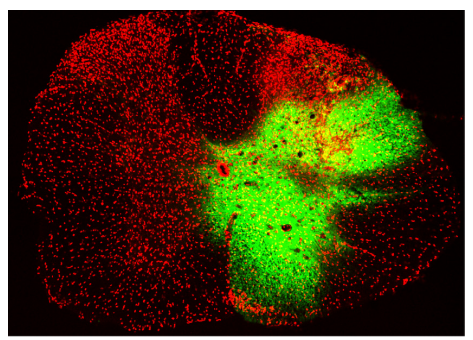

Figure 1. Fluorogold injection site in the thoracic spinal cord. $\boldsymbol{A}$, Schematic overview of the thoracic level of the spinal cord. $\boldsymbol{B}$, Illustration of a representative injection site of Fluorogold (green channel) in the intermediolateral column of the thoracic spinal cord visualized using DAPI nuclear staining (red channel).

leptin is required for normal development of this pathway. Projections of both ARH NPY and POMC neurons to the PVH are disrupted in Lep ${ }^{\mathrm{ob}} / \mathrm{Lep}^{\mathrm{ob}}$ mice, and exogenous leptin treatment of neonatal, but not adult, Lep ${ }^{\text {ob }} /$ Lep $^{\text {ob }}$ mice rescues these peptidergic projections (Bouret et al., 2004b). While leptin plays a central role in promoting the outgrowth of hypothalamic feeding pathways, whether it also specifies patterns of innervation to functionally distinct subcompartments of the PVH is unknown. To address this question, we labeled neuroendocrine or sympathetic preautonomic neurons in the PVH and measured the density of ARH-derived peptidergic inputs onto these identified neurons in adult mice exposed to different postnatal leptin environments. We also assessed the long-term physiological impact of postnatal leptin by evaluating different components of energy balance in these mice. The results indicate that postnatal leptin impacts peptidergic innervation of neuroendocrine and sympathetic preautonomic neurons with both cell type and target-neuron specificity, as well as effects sustained improvements in metabolic function.

\section{Materials and Methods}

Animals and treatments. Newborn leptin-deficient mice (Lep ${ }^{\mathrm{ob}} / \mathrm{Lep}^{\mathrm{ob}}$ ) and their wild-type (WT) littermates were bred by pairing heterozygous male and female mice (The Jackson Laboratory). Litter size was adjusted to 7 pups per litter on the first postnatal day (P1) to ensure adequate and standardized nutrition until weaning. Groups of Lep ${ }^{\mathrm{ob}} / \mathrm{Lep}^{\mathrm{ob}}$ and WT male littermates were treated daily (between 10:00 A.M. and 12:00 P.M.) with intraperitoneal injections of leptin (10 $\mu \mathrm{g} / \mathrm{g}$; Peprotech Inc.; Lep ${ }^{\text {ob }} /$ Lep $^{\mathrm{ob}}$ Leptin group), or vehicle alone (WT Vehicle and Lep ${ }^{\mathrm{ob}} / \mathrm{Lep}^{\mathrm{ob}}$ Vehicle groups), starting at P4, for a total of $11 \mathrm{~d}$ (P4-P14). Mice from all experimental groups were weaned on P22 and maintained in mixed genotype groups until either assessment of metabolic parameters or injection of the tracer for brain neuroanatomical study.

Studies were performed in accordance with the guidelines of the National Institutes of Health and approved by the Saban Research Institute, Children's Hospital Los Angeles' Institutional Committee for the Care and Use of Animals in Research and Education.

Physiological measures. Body weight was monitored daily from P4 to P22 (weaning) and weekly from P23 through P119 ( $n>25$ per group).

Food intake measurements were performed at 11 weeks of age $(n \geq 8$ per group). Mice were housed individually in cages, and food consumption was measured every $12 \mathrm{~h}$ for $3 \mathrm{~d}$ from preweighted portions of food.

Glucose tolerance was performed at $6-7$ weeks of age ( $n \geq 9$ per group). After an overnight fasting, glucose ( $1.5 \mathrm{mg} / \mathrm{g}$ body weight, i.p.) was injected, and blood glucose levels were measured $0,15,30,45,60,90$, 120 , and $150 \mathrm{~min}$ following the glucose challenge. To determine insulin tolerance, 7 - to 8 -week-old mice ( $n \geq 8$ per group) were fasted for $6 \mathrm{~h}$ before testing. A bolus of insulin $(0.75 \mathrm{U} / \mathrm{kg}$ body weight) (HumilinR, Lilly) was administered intraperitoneally, and blood glucose levels were measured $0,15,30,45,60,90$ and $120 \mathrm{~min}$ following the insulin challenge.

Cold challenge was performed at $9-10$ weeks of age ( $n \geq 8$ per group). Mice were placed at $4^{\circ} \mathrm{C}$ in individual cages with food and water ad libitum. Core body temperature was recorded at time 0 (at the onset of cold exposure) and then every $30 \mathrm{~min}$ of cold exposure using a rodent rectal probe (Physitemp).

Twelve-week-old mice were injected intraperitoneally at 9:00 A.M. and 6:30 P.M. with vehicle ( $5 \mathrm{~mm}$ sodium citrate buffer, $\mathrm{pH} 4.0$ ) or leptin ( $2 \mathrm{mg} / \mathrm{kg} ; n \geq 7$ per group) according to the following scheme: vehicle injections for $3 \mathrm{~d}$, followed by leptin injections for $3 \mathrm{~d}$. Food intake was monitored twice daily during injection periods.

Analytical procedures. Blood glucose levels were determined using a Glucometer (FreeStyle Lite, Abbott), and nonesterified free fatty acids (NEFA) using a colorimetric assay (Wako) ( $n \geq 4$ per group).

Histomorphological assessment of white adipose tissue. Intrascapular brown adipose tissue (BAT) and epididymal white adipose tissue (WAT) fat depots were collected at 20 weeks of age ( $n=4$ per group), fixed in $4 \%$ paraformaldehyde solution, embedded in paraffin, cut into $8-\mu \mathrm{m}$-thick sections, and respectively immunostained with a perilipinA/B antibody (Sigma) or stained with hematoxylin and eosin. Representative WAT images were taken with a Zeiss LSM 710 confocal microscope with a $20 \times$ objective. Adipocyte size was determined for WAT with ImageJ software (National Institutes of Health, Bethesda, MD), measuring a minimum of 160 cells per sample.

Retrograde labeling and immunohistochemistry of brain tissue. Retrograde labeling of the fluorescent tracer Fluorogold (FG) (2\% FG; Fluorochrome) was performed under two experimental conditions as previously described (Biag et al., 2012): (1) injection in the spinal cord and (2) injection in the bloodstream intraperitoneally.

To visualize preautonomic neurons that send descending projections to innervate preganglionic sympathetic neurons in the spinal cord, injec- 
A
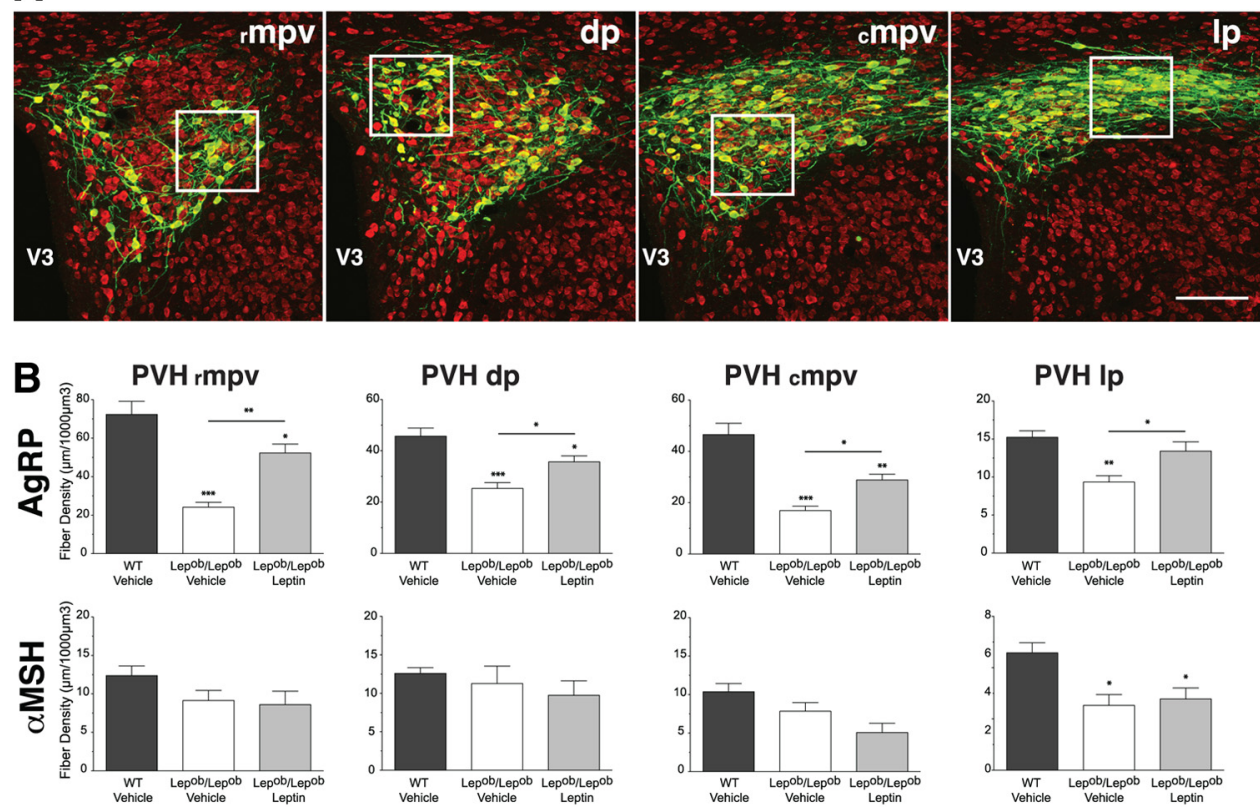

Figure 2. Leptin impacts the peptidergic innervation of preautonomic divisions in adult mouse PVH. $\boldsymbol{A}$, Representative confocal images through the level of the PVH (delineated using antisera against HuC/D, red channel), illustrating the pattern of retrograde labeling following injection of Fluorogold (green channel) in the spinal cord of WT mice at the upper thoracic level (T1-T2). Preautonomic neurons were observed in the rostral and caudal aspects of the ventral medial parvicellular (rmpv and cmpv), dorsal parvicellular (dp) and lateral parvicellular (Ip) parts. Outlined regions identify volumes of quantification. V3, Third ventricle. Scale bar, $100 \mu \mathrm{m}$. $\boldsymbol{B}$, Quantitative comparison of the density of AgRP-and $\alpha M S H$-immunoreactive fibers innervating the mpv, dp, and Ip autonomic parts of the PVH in WT $(n=6)$, Lep ${ }^{\text {ob }} /$ Lep $^{\text {ob }}$ vehicle-treated $(n=5)$, and Lep ${ }^{\text {ob }} /$ Lep ${ }^{\text {ob }}$ leptin-treated mice $(n=6)$. The values represent mean \pm SEM of fiber length per set of volume sampled. Significance between groups was determined using one-way ANOVA followed by pairwise post hoc tests; ${ }^{* * *} p<0.001,{ }^{* *} p<0.01$, and ${ }^{*} p<0.05$ between vehicle- or leptin-treated Lep $^{\mathrm{ob}} /$ Lep $^{\mathrm{ob}}$ mice and their WT littermates. mpv, Ventral zone of the medial parvicellular part; dp, dorsal parvicellular; Ip, lateral parvicellular parts of the PVH.

tions of the retrograde tracer were centered in the intermediolateral column between thoracic vertebrae T1-T2. Alternatively, to label PVH neuroendocrine neurons, we used the permeability of the blood brain barrier at the level of the median eminence and neurohypophysis, where the neuroendocrine PVH neurons send their axon terminals. The blood brain barrier is indeed impaired in these regions, thereby allowing the uptake, retrograde transport and accumulation in cell bodies of the tracer when injected in the blood (Swanson and Kuypers, 1980). For both conditions, mice were killed at $\mathrm{P} 120$, and 5-8 mice were analyzed per treatment group.

At (1) $7 \mathrm{~d}$ or (2) $24 \mathrm{~h}$ following tracer injection, mice were deeply anesthetized with tribromoethanol (Sigma-Aldrich), and perfused transcardially with normal saline, followed by a $4 \%$ paraformaldehyde solution (Electron Microscopy Sciences) in $0.1 \mathrm{~m}$ borate buffer at $\mathrm{pH} 9.5$ for 20 min. Brains were carefully dissected, postfixed for $4 \mathrm{~h}$ in $4 \%$ paraformaldehyde solution containing $20 \%$ sucrose, and then placed overnight in $0.02 \mathrm{M}$ potassium phosphate buffer solution (KPBS) containing $20 \%$ sucrose for cryoprotection. Series of consecutive $20-\mu \mathrm{m}$-thick frozen sections were collected through the PVH of each brain and subsequently processed for multiple immunofluorescence detection.

Sections were blocked overnight in a solution containing $0.3 \%$ Triton $\mathrm{X}-100$ in KPBS and 2\% normal donkey serum or normal goat serum followed by $72 \mathrm{~h}$ incubation with primary antibody at $4^{\circ} \mathrm{C}$ with constant agitation. Sections were incubated with the appropriate secondary antibodies conjugated to Alexa Fluor $(488,568$, and 647; Invitrogen Life Technologies) for $1 \mathrm{~h}$ at room temperature to localize the primary antibodies. To visualize peptidergic inputs onto retrogradely labeled PVH neurons, primary antibodies used were rabbit anti-AgRP (Phoenix Pharmaceuticals), sheep anti- $\alpha$ MSH (Millipore) and the mouse anti-HuC/D, marker of neuronal cells (Invitrogen Life Technologies). Colocalization of AgRP- and $\alpha \mathrm{MSH}$-immunoreactive inputs with the presynaptic markers synaptophysin and synapsin was performed using mouse antisynaptophysin (Synaptic Systems) or rabbit anti-synapsin 1/2 (Synaptic Systems) antisera. Glutamatergic and GABAergic inputs onto identified soma in the PVH were visualized by using rabbit anti-vGlut2 (Synaptic Systems) and guinea-pig anti-VGAT (Synaptic Systems) antisera. The specificities of the antibodies were established by staining with heterologous primary and secondary antibodies and it was determined that there was no cross-reaction between them. All sections were mounted on gelatin-coated slides, and coverslipped using Prolong Gold Antifade mounting medium (Invitrogen Life Technologies).

Image analysis of retrogradely labeled brain sections. Immunostained sections through the PVH were examined on a laser scanning confocal microscope (Zeiss LSM 710) equipped with a $63 \times$ (numerical aperture 1.4) oil-corrected objective and an automated optical configuration optimized for sequential visualization of each fluorescence channel. Morphological landmarks and cytoarchitectonic features (Dong, 2008; Biag et al., 2012) were used to define matched anatomical subregions of the $\mathrm{PVH}$. For each tissue volume sampled, adjacent image planes through the $z$-axis were collected at a frequency of $\sim 0.4 \mu \mathrm{m}$ through the entire thickness of the PVH. To minimize optical distortions, images were deconvolved through an iterative restoration procedure (Volocity restoration software, Improvision; PerkinElmer). Three-dimensional (3D) reconstructions of the image volumes were then prepared for each multichannel set of images using Volocity visualization software. To measure overall densities of labeled fibers in distinct regions of the PVH, images were binarized, skeletonized and the total fiber length contained in the image volume was measured using Volocity quantitation software. To resolve (1) presynaptic markers for GABA (vesicular GABA transporter) and glutamatergic terminals (vesicular glutamate transporter 2) and (2) terminals labeled for AgRP and $\alpha \mathrm{MSH}$ that are apposed to soma of FG-labeled neuronal cell bodies, confocal images through the PVH were post-processed by using Volocity $3 \mathrm{D}$ visualization software. The density of neuronal inputs to identified PVH neurons was quantified using Volocity image analysis software. Each putative neuronal input was defined as a 3-dimensional object in direct contact (voxel to voxel apposition) with the postsynaptic target neuron labeled with $\mathrm{Hu} / \mathrm{CD}$ (Movie 1). Retrogradely transported FG mainly accumulates in the lysosomal compartment (Persson and Havton, 2009). Therefore, to define the somatic borders of preautonomic or neuroendocrine neurons in the quantitation process the somatic marker $\mathrm{HuC} / \mathrm{D}$ was preferred to the native FG fluorescence to avoid inaccurate delineation of the somatic compartment. 
A
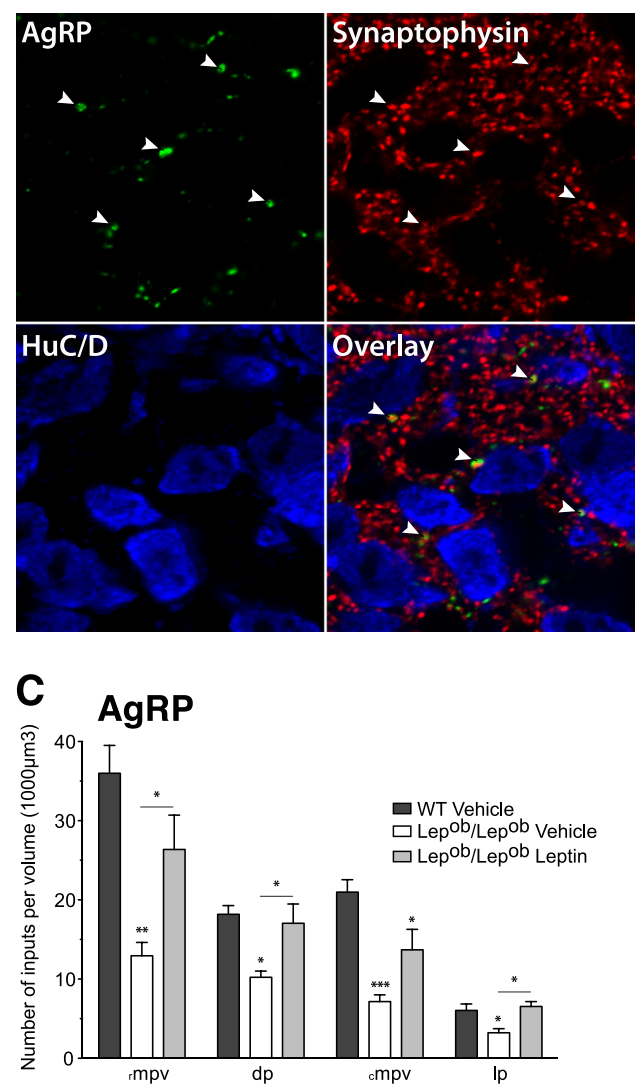

B
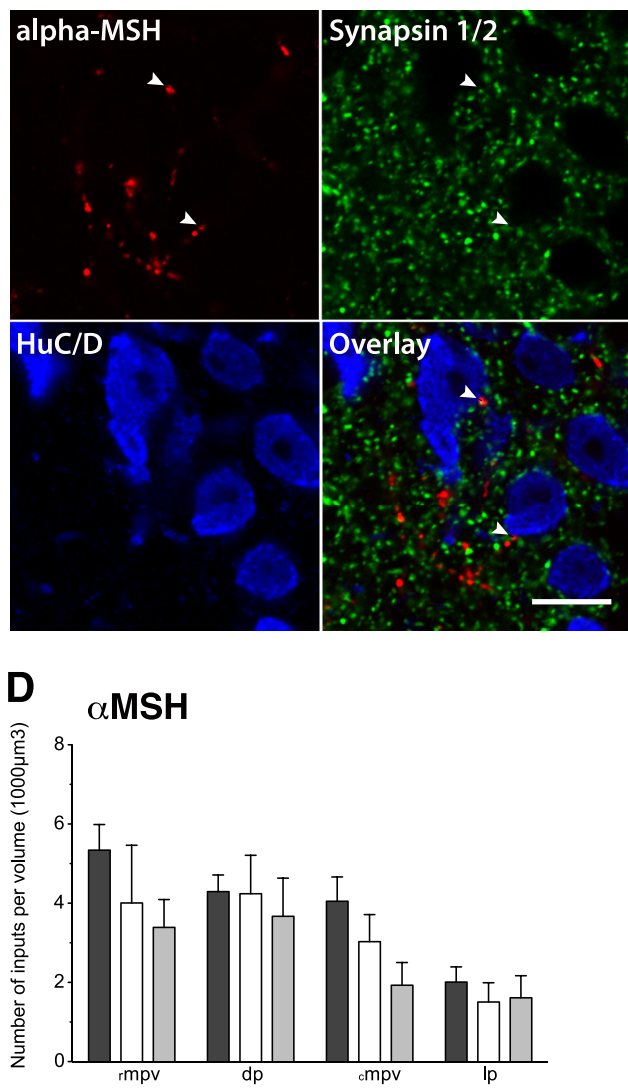

Figure 3. Leptin impacts the axonal terminal densities of preautonomic divisions in adult mouse PVH. $\boldsymbol{A}, \boldsymbol{B}$, Single confocal image: plane of HuC/D, AgRP, synaptophysin (A) and HuC/D, $\alpha$ MSH, synapsin 1/2 (B) triple-labeled immunofluorescence at the level of the PVH of WT mouse. Arrows indicate examples of dual-labeled AgRP and synaptophysin $(\boldsymbol{A})$, or $\alpha$ MSH- and synapsin 1/2-immunopositive $(\boldsymbol{B})$ terminals in close contact with PVH soma (identified using antisera against HuC/D). Scale bar, $10 \mu \mathrm{m}$. $\boldsymbol{C}, \boldsymbol{D}, \mathbf{Q}$ uantitative comparison of the number of AgRP $(\boldsymbol{C})$ and $\alpha \mathrm{MSH}$-IR (D) varicosities in close apposition to spinal cord projecting neurons of the PVH in WT $(n=6)$, Lep ${ }^{\text {ob }} /$ Lep $^{\text {ob }}$ vehicle-treated $(n=5)$, and Lep ${ }^{\text {ob }} /$ Lep ${ }^{\text {ob }}$ leptin-treated mice $(n=6)$. The values represent mean \pm SEM of density of inputs. Significance between groups was determined using one-way ANOVA followed by pairwise post hoc tests; ${ }^{* * *} p<0.001,{ }^{* *} p<0.01$, and ${ }^{*} p<0.05$ between vehicle- or leptin-treated Lep ${ }^{\mathrm{ob}} /$ Lep $^{\mathrm{ob}}$ mice and their WT littermates.

Using a subtractive approach, we performed the quantification of terminals apposed to identified PVH neurons, as defined by HuC/D immunostaining, which contain the retrograde tracer FG (Movie 1). The number of peptidergic or presynaptic inputs was normalized to a set volume of somal marker $\left(1000 \mu \mathrm{m}^{3}\right)$ and expressed as a density. This image processing routine was optimized for unambiguous identification of closely apposed nerve terminals onto PVH neurons. The accuracy of this quantitative procedure was verified by comparing it with results obtained by manual counting in a limited set of experimental material. All modules of Volocity software were run on a Mac Pro computer (Apple) supported by a dedicated high performance cluster computing system (Dell Computer) and the Imaging Computing Server utility software (Improvision).

Terminology. The use of the terms "apposition," "close contact," or "terminal" in this article refers to histochemically labeled axonal structures that are in direct contact with a cell body that has been labeled with a specific neuronal marker (HuC/D). Labeled boutons (typically 1-3 $\mu \mathrm{m}$ in diameter) were visualized by using histochemical markers $(\alpha \mathrm{MSH}$, AgRP, VGAT, and vGlut2) and resolved as "touching objects" that are immediately adjacent to cell bodies (with no unlabeled voxel between the terminal and the cell body) in 3D reconstructions of tissue volumes, according to parameters specified in Volocity software. Although determination that a particular point of contact between an axon terminal and a target cell qualifies as a morphologically defined synapse requires ultrastructural analysis, the densities of such contacts likely reflects the overall density of neurochemically defined inputs to populations of identified neurons in the PVH. Because AgRP is colocalized with NPY in the ARH and its expression is increased in Lep ${ }^{\mathrm{ob}} / \mathrm{Lep}^{\mathrm{ob}}$ mice, changes in AgRP immunostained terminals likely reflect changes in axon density. Changes in $\alpha \mathrm{MSH}$ staining may reflect combined changes in axon density and gene expression, as discussed previously (Bouret et al., 2004b).

Statistics. Significance was tested using Prism software (GraphPad Software Inc.). One-way ANOVA followed by a pairwise post hoc test was used to test for significant differences between experimental groups; a $p$ value of 0.05 or less was defined as significant. The statistical significance of differences in body weight, GTT, ITT, and core temperature (cold exposure) was determined using two-way ANOVA followed by a post hoc test.

\section{Results}

Leptin specifies the peptidergic innervation of preautonomic neurons in the PVH

To determine whether feeding-related neuropeptidergic terminal fields projecting to preautonomic (PA) neuronal components of the PVH are dependent on leptin, we examined the density of AgRP- and $\alpha \mathrm{MSH}$-containing fibers in regions of the PVH that contain high densities of preautonomic neurons in adult Lep ${ }^{\mathrm{ob}} /$ Lep $^{\text {ob }}$ mice. To visualize these neurons in the PVH we injected a retrograde tracer FG into the upper thoracic level of the spinal cord (see injection site, Fig. $1 A, B$ ), which contains preganglionic sympathetic motor neurons of the intermediolateral column (Luiten et al., 1985). As previously described (Biag et al., 2012), dense clusters of FG-labeled neurons were located in the lateral hypothalamic area and in discrete components of the PVH. The 
highest concentrations of FG-labeled PA neurons were in the caudal two-thirds of the PVH including the dorsolateral region of the medial parvicellular compartment (PVHmpv) at the level of the PVH, posterior magnocellular part, medial zone, as well as in the caudal most part of the PVHmpv. FG-labeled PA neurons were also clustered in the dorsal parvicellular compartment of the PVH (PVHdp) (Fig. $2 A)$. Finally, at more caudal levels, the lateral parvicellular compartment of the PVH (PVHlp), just rostral to the dorsomedial nucleus of the hypothalamus (DMH) also contained a high density of FG-labeled cells (Fig. 2A, last panel). The majority of these FG-labeled neurons were located ipsilateral to the injection site, but a few cells were also detected on the contralateral PVH.

AgRP-immunoreactive (AgRP-IR) fibers were not uniformly distributed in all parts of the PVH that contain PA neurons. (Fig. 2B). The highest densities of AgRP-IR fibers were in the ventral part of the PVHmpv, and in the PVHdp. Densities of AgRP-IR fibers were considerably lower in the PVHlp. In sharp contrast, the density of $\alpha \mathrm{MSH}$-IR fibers appeared to be distributed homogeneously in all autonomic regions analyzed. The density of AgRP-IR fibers was severely reduced in all regions of the $\mathrm{PVH}$ that contain PA neurons in adult Lep ${ }^{\mathrm{ob}} / \mathrm{Lep}^{\mathrm{ob}}$ mice that received vehicle treatment postnatally, compared with that observed in WT littermates (Fig. 2B). In contrast to AgRP, the density of $\alpha \mathrm{MSH}$-IR fibers was only reduced in the PVHlp of Lep ${ }^{\mathrm{ob}} / \mathrm{Lep}^{\mathrm{ob}}$ mice (Fig. $2 B$; densities of $\alpha \mathrm{MSH}-\mathrm{IR}$ fibers in other PA compartments sampled (mpv and dp) did not appear to be affected by leptin deficiency.

To determine whether postnatal leptin exposure could reverse the decreased densities of AgRP-IR and $\alpha$ MSH-IR fibers observed in Lep ${ }^{\text {ob }} /$ Lep $^{\text {ob }}$ mice, neonatal Lep ${ }^{\mathrm{ob}} / \mathrm{Lep}^{\mathrm{ob}}$ mice were treated intraperitoneally with recombinant leptin daily from $\mathrm{P} 4$ through P14. These exogenous postnatal leptin treatments were sufficient to significantly increase the density of AgRP-IR fibers in all PA compartments of the PVH to levels similar to those of their WT littermates (Fig. $2 B$ ). In contrast, postnatal leptin treatment did not appear to influence the densities of $\alpha \mathrm{MSH}$-IR in the regions analyzed (Fig. $2 B$ ). Thus, in keeping with earlier observations, leptin deficiency impairs the development of AgRP-containing projections from the ARH to regions of the PVH that contain PA neurons, and daily treatment with leptin during a discrete postnatal period is sufficient to rescue the density of AgRP-IR fibers in these parts of the PVH.

Although the regional analysis of changes in peptidergic fibers in regions that contain PA neurons suggest that innervation of these neurons is similarly affected, we used confocal microscopy combined with computer-assisted 3D rendering and image anal- ysis to measure the number of AgRP- and $\alpha \mathrm{MSH}$-containing terminals that are in close apposition to FG-labeled PVH neurons. We first confirmed that such putative peptidergic inputs to PVH neurons were also immunoreactive for either synaptophy$\sin$ (AgRP immunostaining) or synapsin 1/2 ( $\alpha \mathrm{MSH}$ immunostaining), suggesting that these points of contact do indeed represent synapses (Fig. $3 A, B$ ). The results of the analysis confirmed that the density of AgRP neuronal inputs onto identified PA neurons was decreased significantly in Lep ${ }^{\mathrm{ob}} / \mathrm{Lep}^{\mathrm{ob}}$ mice compared with that of WT Vehicle littermates (Fig. 3C). However, the density of $\alpha \mathrm{MSH}$ neuronal inputs appeared to be similar regardless of leptin levels (Fig. $3 D$ ). Furthermore, daily intraperitoneal injections of leptin to Lep ${ }^{\mathrm{ob}} / \mathrm{Lep}^{\mathrm{ob}}$ neonates significantly increased the average number of AgRP-IR neuronal inputs onto PA neurons to levels comparable to that of WT littermates in nearly all of the PA divisions of the PVH analyzed (Fig. 3C). These changes in terminal density are not due to leptin-induced changes in cell size because the average volumes containing 
A
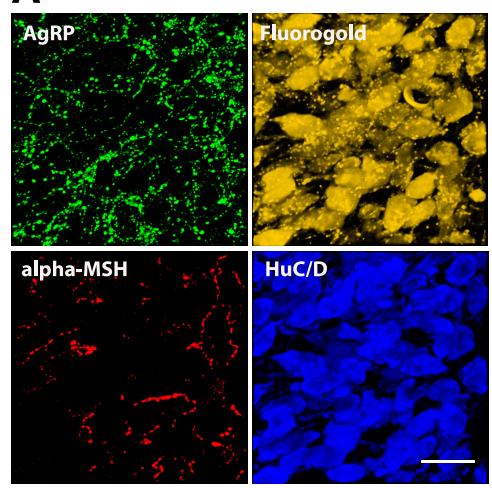

B
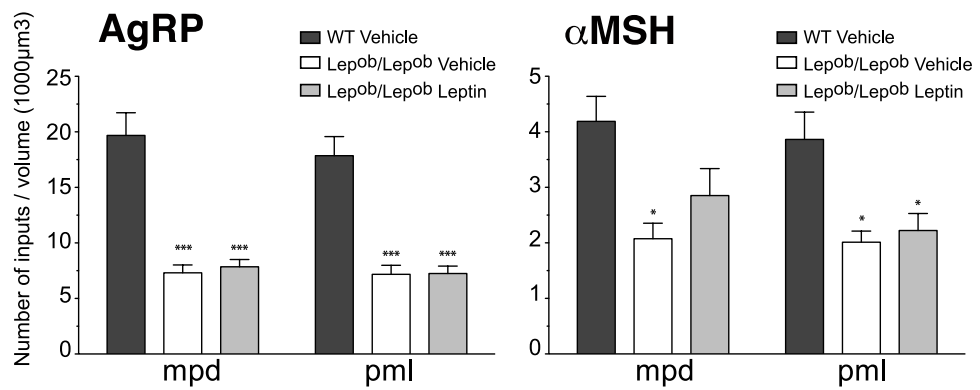

Figure 5. Leptin modulates neuropeptidergic terminal densities to neurosecretory neurons in the adult PVH. $\boldsymbol{A}$, High magnification confocal images of AgRP, $\alpha M S H, F G$ and HuC/D immunofluorescence in the neurosecretory division of the PVH. Threedimensional rendering view of the image volume depicting the quantification of terminal densities (AgRP, blue objects and $\alpha \mathrm{MSH}$, pink objects) in close contact with neuronal cells (HuC/D) filled with FG retrograde tracer (orange objects, right). Post-processing, reconstruction, and quantitative analyses of confocal images were performed using Improvision Volocity software. Scale bar, 20 $\mu \mathrm{m} . \boldsymbol{B}$, Quantitative comparison of AgRP-and $\alpha \mathrm{MSH}-\mathrm{IR}$ varicosities in close apposition to neurosecretory neurons of the PVH in WT $(n=6)$, Lep ${ }^{\mathrm{ob}} /$ Lep $^{\mathrm{ob}}$ vehicle-treated $(n=5)$, and Lep ${ }^{\mathrm{ob}} /$ Lep $^{\mathrm{ob}}$ leptin-treated mice $(n=6)$. The values represent mean \pm SEM of number of inputs per volume analyzed. Significance between groups was determined using one-way ANOVA followed by pairwise post hoc tests; ${ }^{* * *} p<0.001$ and ${ }^{*} p<0.05$ between vehicle- or leptin-treated Lep ${ }^{\mathrm{ob}} /$ Lep $^{\mathrm{ob}}$ mice and their WT littermates. mpd, Medial parvicellular part, dorsal zone; pml, posterior magnocellular part, lateral zone of the PVH.

HuC/D- and FG-labeled (preautonomic) neurons in the PVH volumes sampled were not altered significantly by leptin deficiency (data not shown).

Together, these observations suggest that the density of AgRPcontaining inputs onto PA neurons in the PVH is dependent on leptin and that administration of leptin during the early postnatal period is sufficient to restore normal patterns of cellular innervation in Lep ${ }^{\mathrm{ob}} / \mathrm{Lep}^{\mathrm{ob}}$ mice. Conversely, inputs to PA neurons containing melanocortin peptides appear to be leptin-independent, suggesting a cell type-specific modulation of peptidergic innervation of PA neurons by leptin during postnatal development.

\section{Postnatal leptin exposure does not rescue peptidergic} innervation of neuroendocrine neurons in the PVH

To assess whether leptin is required for normal innervation patterns to neuroendocrine (NE) neurons in the PVH, we labeled neurons with projections to regions that lack a blood-brain barrier. In the PVH, NE neurons project to the median eminence or to the posterior lobe of the pituitary and can be labeled by infusions of retrograde tracers into the blood. Injections of FG into the bloodstream of WT and Lep ${ }^{\mathrm{ob}} / \mathrm{Lep}^{\mathrm{ob}}$ mice resulted in clusters of intensely labeled neurons in both the arcuate and supraoptic hypothalamic nuclei, as well as in several components of the PVH, as described previously (Biag et al., 2012). In these mice, FG-labeled neurons were located in the magnocellular and par- vicellular components of the $\mathrm{PVH}$, regions known to contain neuroendocrine neurons that project to the median eminence.

To determine whether feeding-related neuropeptidergic terminal fields projecting to neurosecretory components of the PVH are dependent on leptin, we examined the density of AgRP- and $\alpha \mathrm{MSH}$-containing fibers in two regions of the PVH that contain high densities of neurosecretory neurons: the dorsal region of the medial parvicellular dorsal (mpd) and, at more caudal levels, a region, designated here as PVHpml, composed primarily of magnocellular neurons (Fig. 4A). Although AgRP- and $\alpha \mathrm{MSH}-$ immunoreactive (IR) fibers were codistributed in parts of the PVH that contain NE neurons, clear differences were apparent in their regional densities. In the PVH of both vehicle-injected WT and Lep ${ }^{\mathrm{ob}} / \mathrm{Lep}^{\mathrm{ob}}$ mice, there were four to five times fewer $\alpha \mathrm{MSH}$-IR fibers compared with AgRP-IR fibers (Fig. $4 B$ ). In adult Lep ${ }^{\mathrm{ob}} / \mathrm{Lep}^{\mathrm{ob}}$ mice, the density of AgRP- and $\alpha \mathrm{MSH}$-IR fibers were reduced in both the PVHmpd and PVHpml, compared with their WT littermates (Fig. 4B). Quantitative analysis of peptidergic fiber densities in regions of the PVH that contain NE neurons revealed that leptin treatment did not restore the density of AgRP- or $\alpha$ MSH-IR fibers in Lep ${ }^{\text {ob } / ~}$ Lep ${ }^{\mathrm{ob}}$ mice levels observed in their WT littermates (Fig. 4B).

Similar to the analysis of peptidergic innervation of PA neurons in the PVH, the dependence of cellular patterns of innervation onto neurosecretory $\mathrm{PVH}$ neurons was assessed by measuring densities of AgRP- and $\alpha \mathrm{MSH}-$ containing nerve terminals in close apposition to NE neurons in the PVH (Fig. 5A). Consistent with the regional analysis, the density of AgRP and $\alpha \mathrm{MSH}$ neuronal inputs onto NE neurons was significantly decreased in $\mathrm{Lep}^{\mathrm{ob}} / \mathrm{Lep}^{\mathrm{ob}}$ mice compared with that of WT littermates, in both the PVHmpd and PVHpml (Fig. $5 B)$. Moreover, neonatal leptin treatment failed to significantly increase the number of AgRP- or $\alpha \mathrm{MSH}$-IR neuronal inputs onto neurosecretory neurons in both compartments analyzed (Fig. $5 B$ ). Together, these data suggest that leptin exposure is required to maintain normal patterns of peptidergic innervation of NE neurons in the PVH. However, an early postnatal treatment with leptin is not sufficient to rescue the innervation deficit caused by leptin insufficiency.

GABAergic and glutamatergic innervation of functionally identified PVH neuronal compartments is not impacted by leptin exposure

To determine whether leptin is required to maintain normal patterns of GABAergic or glutamatergic connectivity in the $\mathrm{PVH}$, we compared the density of nerve terminals containing presynaptic markers for GABAergic or glutamatergic neurons within functionally distinct compartments of the PVH (e.g., neuroendocrine vs autonomic) (Fig. 6A). In contrast to the results obtained for neuropeptide-containing neurons, densities of VGAT- and 
A
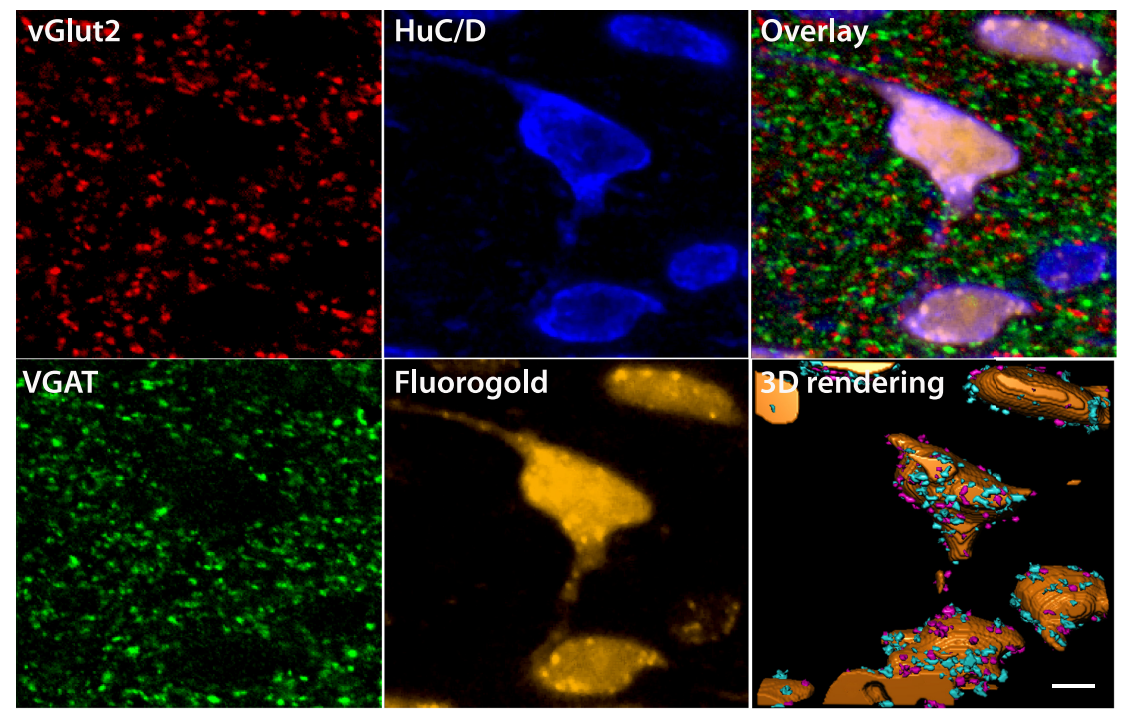

B
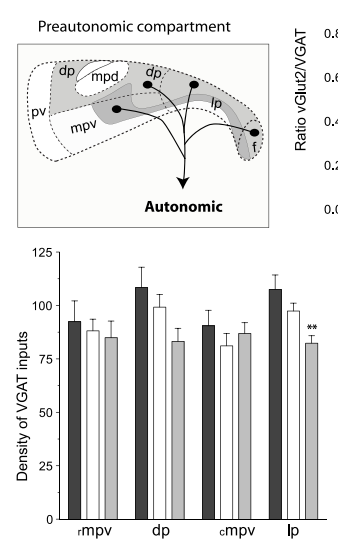
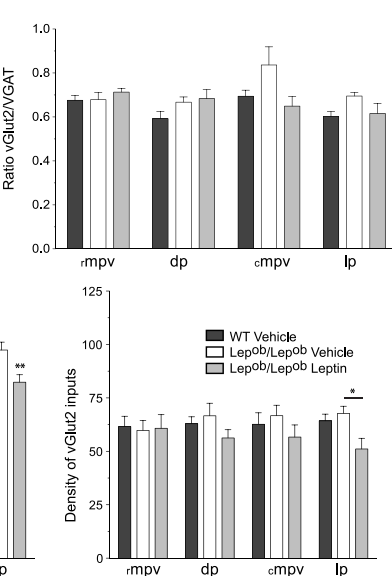

C
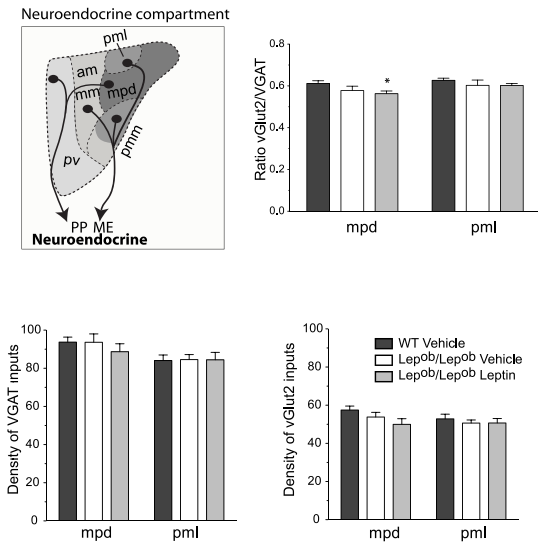

Figure 6. GABAergic and glutamatergic innervation of functionally identified adult PVH neuronal compartments. $\boldsymbol{A}$, Confocal images illustrating GABAergic (VGAT) and Glutamatergic (vGlut2) immunoreactive appositions on preautonomic neurons visualized by the fluorescent dye Fluorogold following spinal cord injection. Scale bar, $5 \mu \mathrm{m}$. $\boldsymbol{B}, \boldsymbol{C}, \mathrm{Quantitative} \mathrm{comparison}$ of the density or ratio of vGlut2-IR over VGAT-IR terminals onto preautonomic $(\boldsymbol{B})$ or neurosecretory ( $\boldsymbol{C}$ ) neurons in the PVH in WT $(n=6)$, Lep ${ }^{\mathrm{ob}} /$ Lep $^{\mathrm{ob}}$ vehicle-treated $(n=5)$, and Lep ${ }^{\mathrm{ob}} /$ Lep ${ }^{\mathrm{ob}}$ leptin-treated mice $(n=6)$. The values represent mean \pm SEM of number of inputs per volume sampled. Significance between groups was determined using one-way ANOVA followed by pairwise post hoc tests ${ }^{* *} p<0.01,{ }^{*} p<0.05$ between vehicle- or leptin-treated Lep ${ }^{\mathrm{ob}} /$ Lep ${ }^{\mathrm{ob}}$ mice and their WT littermates. am, Anterior magnocellular part; dp, dorsal parvicellular part; f, forniceal part; mm, medial magnocellular part; mpv, medial parvicellular part, ventral zone, rostral (rmpv) and caudal aspects (cmpv); mpd, medial parvicellular part, dorsal zone; Ip, lateral parvicellular part; pmm, posterior magnocellular part, medial zone; pml, posteriormagnocellular part, lateral zone; pv, periventricular part of the PVH; IML, intermediolateral column; PP, posterior pituitary; ME, median eminence. Schematics are adapted from Biag et al. (2012).

vGlut2-IR terminals onto neurosecretory and preautonomic neurons displayed only minor decreases in Lep ${ }^{\text {ob }} / \mathrm{Lep}^{\text {ob }}$ mice. In addition, the overall ratio of excitatory to inhibitory inputs onto neurosecretory or preautonomic neurons in the PVH was not influenced by leptin exposure during the developmental period. Furthermore, daily intraperitoneal injections of exogenous leptin to Lep ${ }^{\text {ob }} /$ Lep $^{\text {ob }}$ mice from P4 to P14 only slightly decreased densities of VGAT and vGlut2 terminals onto neuroendocrine and preautonomic compartments of the PVH (Fig. 6B,C). Together, these data show that alterations of leptin availability in early development are not translated into significant changes in cellular ratios of inhibitory and excitatory synapses onto functional subpopulations of PVH neurons. It could indicate that the action of leptin occurs through a cell type-specific mechanism.

\section{Postnatal leptin treatment reduces body weight and food} intake of adult Lep ${ }^{\mathrm{ob}} / \mathrm{Lep}^{\mathrm{ob}}$ mice

To explore the long-term physiological impact of postnatal leptin exposure, leptin-deficient mice and WT littermates were treated during the postnatal period (P4-P14) with exogenous leptin (10 $\mu \mathrm{g} / \mathrm{g}$ ) (Lep ${ }^{\text {ob }} / \mathrm{Lep}^{\text {ob }}$ Leptin group) or vehicle alone (WT Vehicle and Lep ${ }^{\mathrm{ob}} / \mathrm{Lep}^{\mathrm{ob}}$ Vehicle groups) and their growth curves monitored daily from P4 to P22 (weaning) and weekly from P23 to P92. Consistent with previous reports, body weight did not differ between Lep ${ }^{\mathrm{ob}} / \mathrm{Lep}^{\mathrm{ob}}$ and WT mice throughout the postnatal period (P4-P22). However, treatment of postnatal Lep ${ }^{\text {ob }} / \mathrm{Lep}^{\text {ob }}$ mice with leptin (P4-P14) exerted a moderate but significant impact on body weight with Lep ${ }^{\mathrm{ob}} /$ Lep $^{\mathrm{ob}}$ Leptin mice exhibiting a reduced rate of weight gain from $\mathrm{P} 15$ to $\mathrm{P} 19$, which normalized by weaning (Fig. 7A)

In adulthood (after P23), Lep ${ }^{\text {ob }} /$ Lep $^{\text {ob }}$ leptin-treated mice remained markedly obese compared with WT littermates and by $5-6$ weeks of age were significantly lighter compared with Lep ${ }^{\text {ob} /}$ Lep $^{\text {ob }}$ vehicle-treated littermates (4.32\% at P92). These changes in body weight persisted throughout adulthood (up to 13 weeks of age; Fig. $7 B$ ). Postnatal leptin also normalized the elevated food consumption that is characteristic of Lep ${ }^{\mathrm{ob}} / \mathrm{Lep}^{\mathrm{ob}}$ mice (Fig. 7C). In leptin-treated Lep ${ }^{\mathrm{ob}} / \mathrm{Lep}^{\mathrm{ob}}$ mice there were significant reduc- 

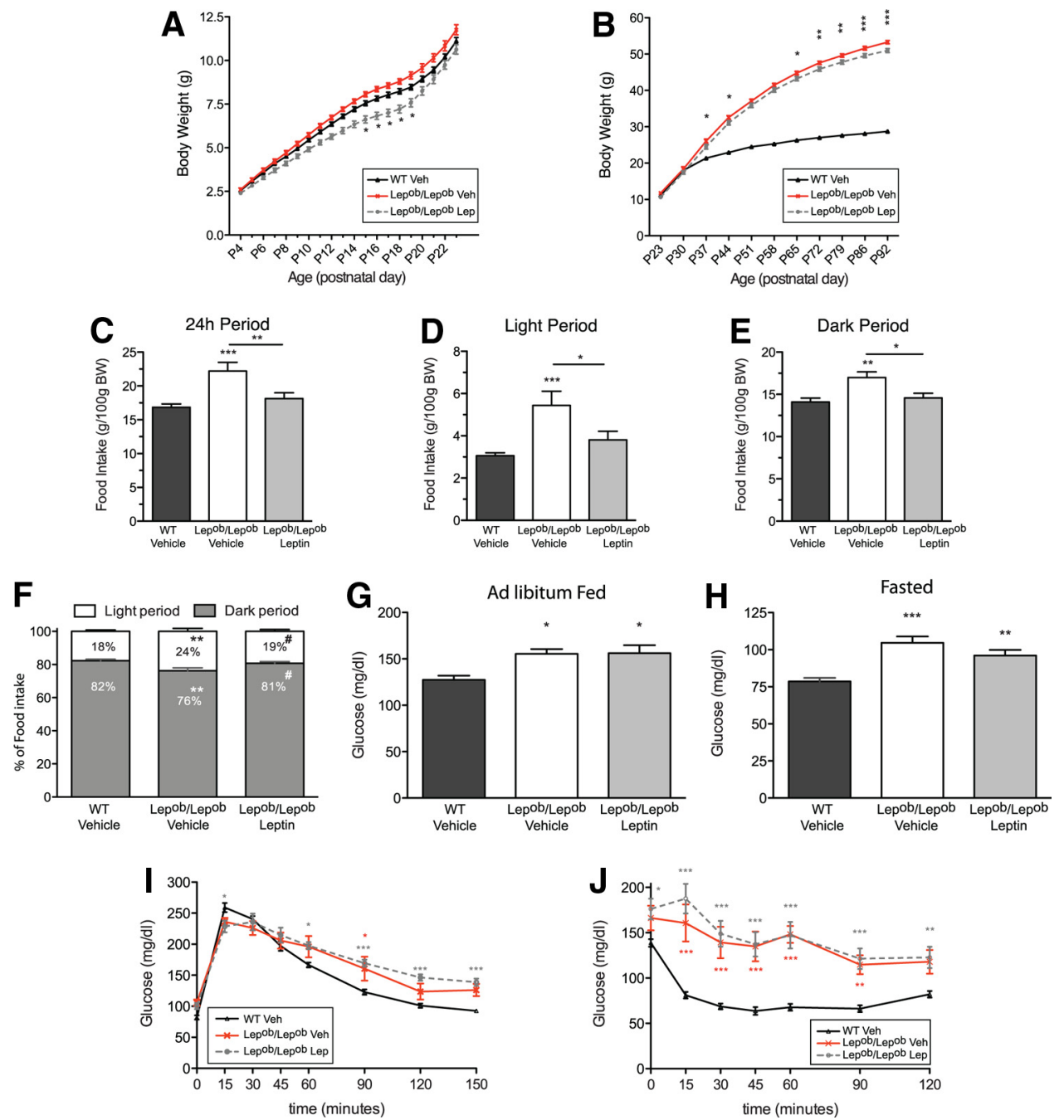

Figure 7. Postnatal leptin exposure reduces body weight gain and food intake of adult leptin-deficient mice. $\boldsymbol{A}, \boldsymbol{B}$, Preweaning $(\boldsymbol{A})$ and postweaning $(\boldsymbol{B})$ growth curves of WT vehicle-treated (WT Veh), Lep ${ }^{\mathrm{ob}} /$ Lep $^{\mathrm{ob}}$ vehicle-treated (Lep ${ }^{\mathrm{ob}} /$ Lep ${ }^{\mathrm{ob}}$ Veh), and Lep ${ }^{\mathrm{ob}} /$ Lep ${ }^{\mathrm{ob}}$ leptin-treated (Lep ${ }^{\mathrm{ob}} /$ Lep ${ }^{\mathrm{ob}}$ Lep), male mice $(n>25$ per group). $\boldsymbol{C}-\boldsymbol{E}$, Food intake measurement normalized to body weight (BW) per $24 \mathrm{~h}(\boldsymbol{C})$ and during the light period $(\boldsymbol{D})$ and dark period $(\boldsymbol{E})$ of 11-week-old WT Vehicle $(n=15)$, Lep ${ }^{\mathrm{ob}} /$ Lep ${ }^{\mathrm{ob}}$ Vehicle $(n=8)$, and Lep ${ }^{\mathrm{ob}} /$ Lep ${ }^{\mathrm{ob}}$ Leptin male mice $(n=12)$. $\boldsymbol{F}$, Graphical representation of the relative distribution of total food intake during the light and dark periods. ${ }^{\#} p<0.05$ between vehicle- and leptin-treated Lep ${ }^{\mathrm{ob}} / \mathrm{Lep}^{\mathrm{ob}}$ mice. Basal glucose levels in ad libitum fed $(\boldsymbol{G})$ or $14 \mathrm{~h}$ fasting $(\boldsymbol{H})$ male WT $(n=15)$, Lep ${ }^{\mathrm{ob}} /$ Lep ${ }^{\mathrm{ob}}$ vehicle-treated $(n=9)$, and Lep ${ }^{\mathrm{ob}} /$ Lep ${ }^{\mathrm{ob}}$ leptin-treated male mice $(n=12)$ at $6-8$ weeks of age. $\boldsymbol{I}$, Following a bolus of glucose (intraperitoneal injection), glucose tolerance test (GTT) was analyzed in 6- to 7-week-old mice. J, Insulin tolerance test (ITT) was assessed following an insulin bolus in 7- to 8-week-old WT $(n=15)$, Lep ${ }^{\mathrm{ob}} /$ Lep ${ }^{\mathrm{ob}}$ Vehicle $(n=9)$, and Lep ${ }^{\mathrm{ob}} /$ Lep ${ }^{\mathrm{ob}}$ Leptin male mice $(n=12)$. All data are mean \pm SEM. One-way or two-way ANOVA and pairwise post hoc tests were performed for each dependent variable. ${ }^{*} p<0.05$, ${ }^{* *} p<0.01$, and ${ }^{* * *} p<0.001$. In $\boldsymbol{A}$ and $\boldsymbol{B}$, only the significance between vehicle- or leptin-treated Lep ${ }^{\mathrm{ob}} / \mathrm{Lep}^{\mathrm{ob}}$ mice is represented.

tions in daily food intake, in both light and dark periods, compared with Lep ${ }^{\mathrm{ob}} /$ Lep $^{\text {ob }}$ Vehicle mice (Fig. $7 D, E$ ). Moreover, postnatal leptin normalized circadian patterns of eating, which are disrupted in Lep ${ }^{\mathrm{ob}} / \mathrm{Lep}^{\mathrm{ob}}$ mice (Ho and Chin, 1988). Lep ${ }^{\mathrm{ob}} /$ Lep $^{\text {ob }}$ Vehicle mice ate $23.78 \pm 1.76 \%$ of their food in the light period compared with $17.69 \pm 0.83 \%$ for WT Vehicle mice (Fig. $7 F$ ), whereas leptin-treated mice ate $19.33 \pm 1.07 \%$ during the light period suggesting that postnatal leptin exposure was able to restore the temporal distribution of meals in adulthood. Lep ${ }^{\mathrm{ob}}$ / Lep $^{\text {ob }}$ mice also display perturbations in glucose homeostasis so we performed glucose tolerance tests at P35 and insulin tolerance tests at P45 on Lep ${ }^{\text {ob }} /$ Lep $^{\text {ob }}$ mice exposed to postnatal leptin. As expected, leptin-deficient mice displayed increased fasted and fed glucose levels compared with their wild-type littermates (Fig. $7 G, H)$, but neonatal leptin treatment of Lep ${ }^{\text {ob }} /$ Lep $^{\text {ob }}$ mice had no discernable effect on fasted or fed glucose levels, nor were improvements detected in either GTT or ITT in leptin-treated Lep $^{\text {ob }} /$ Lep $^{\text {ob }}$ mice compared with vehicle-treated controls (Fig. $7 I, J$ ).
Postnatal leptin treatment normalizes temperature regulation

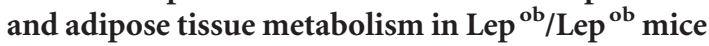

Because postnatal leptin treatment rescued innervation of preautonomic neurons in the PVH we evaluated whether these neuroanatomical changes were associated with a normalization of peripheral measures of autonomic function. We first assessed the ability of Lep ${ }^{\mathrm{ob}} / \mathrm{Lep}^{\mathrm{ob}}$ mice to maintain their core body temperature when exposed to a cold environment. Lep ${ }^{\text {ob }} /$ Lep $^{\text {ob }}$ mice treated postnatally with leptin displayed significantly improved maintenance of body temperature when placed in a cold environment $\left(4^{\circ} \mathrm{C}\right)$, compared with vehicle-treated controls (Fig. $8 \mathrm{~A}$ ). This finding suggests that postnatal leptin exposure permanently improves thermoregulation, perhaps through normalization of autonomic responses to cold challenge. It is more difficult to maintain body temperature in the fasted state due to a reduction in sympathetic activity impacting brown adipose tissue. Whereas postnatally leptin-treated Lep ${ }^{\mathrm{ob}} / \mathrm{Lep}^{\mathrm{ob}}$ mice exhibit hypothermia in an $\mathrm{ad}$ libitum feeding state, they performed better in maintaining their body core temperature when fasted for $14 \mathrm{~h}$ (Fig. $8 B-D$ ), arguing in favor 
of an improved sympathetic response of BAT in the leptin-treated group. Leptindependent improvements in BAT responses were also consistent with fat pad histology. Histomorphological analysis of epididymal WAT revealed a significant decrease in mean white adipocyte cell size in adult Lep ${ }^{\mathrm{ob}} / \mathrm{Lep}^{\mathrm{ob}}$ mice that received postnatal leptin treatment, compared with that of Lep $^{\text {ob }} / \mathrm{Lep}^{\text {ob }}$ mice treated with vehicle alone (Fig. $8 E$ top, $F$ ). Similarly, hematoxylin and eosin staining of interscapular BAT in adult Lep $^{\text {ob }} / \mathrm{Lep}^{\text {ob }}$ mice treated with leptin postnatally appeared smaller than those in the vehicletreated mice (Fig. 8E, bottom). Finally, plasmatic NEFA concentrations, which represent an index of lipid mobilization, were significantly decreased in Lep ${ }^{\mathrm{ob}} /$ Lep ${ }^{\text {ob }}$ mice that received postnatal leptin, compared with the vehicle-treated group (Fig. 8G). Together these data suggest that treatment of Lep ${ }^{\text {ob }} /$ Lep $^{\text {ob }}$ mice with leptin during postnatal life enhances responses to sympathetic stimuli in adulthood, and improves sympathetic outflow.

\section{Postnatal leptin treatment improves leptin sensitivity of adult Lep ${ }^{\mathrm{ob}} / \mathrm{Lep}^{\mathrm{ob}}$ mice}

Hypothalamic circuits that relay leptin signals are an important component of leptin's ability to regulate food intake (Buettner et al., 2008). Therefore, if postnatal leptin is required for normal development of these pathways then Lep ${ }^{\mathrm{ob}} /$ Lep $^{\mathrm{ob}}$ mice that receive leptin during the postnatal critical period for development of ARH projections to the PVH should be more responsive to leptin. To test this hypothesis, we examined physiological responses to low-dose leptin treatment at 12 weeks of age. Adult mice were injected twice daily with Sodium Citrate (vehicle solution) for $3 \mathrm{~d}$ followed by $3 \mathrm{~d}$ of recombinant leptin $(2 \mathrm{mg} / \mathrm{kg}$ ) and food intake monitored twice daily during the 2 injection periods. Lep ${ }^{\text {ob }} /$ Lep $^{\text {ob }}$ mice treated with leptin during postnatal life (PN-L) appeared to be significantly more responsive to leptin in adulthood. Leptin injections reduced food intake 2.43-fold in PN-L Lep ${ }^{\mathrm{ob}} /$ Lep $^{\mathrm{ob}}$ mice, but only 1.76 fold in vehicle-treated controls (Fig. 9A). The inhibitory effect of leptin on food intake during leptin treatment, appeared more pronounced in adult PN-L Lep ${ }^{\mathrm{ob}} /$ Lep ${ }^{\text {ob }}$ mice compared with adult PN-V

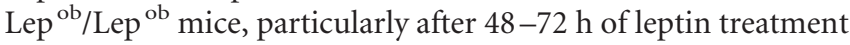
(Fig. 9B). The enhanced ability of leptin to reduce food intake in Lep $^{\text {ob }} /$ Lep $^{\text {ob }}$ mice does not seem to be due to alterations in numbers of neurons in the ARH that express leptin receptors. We
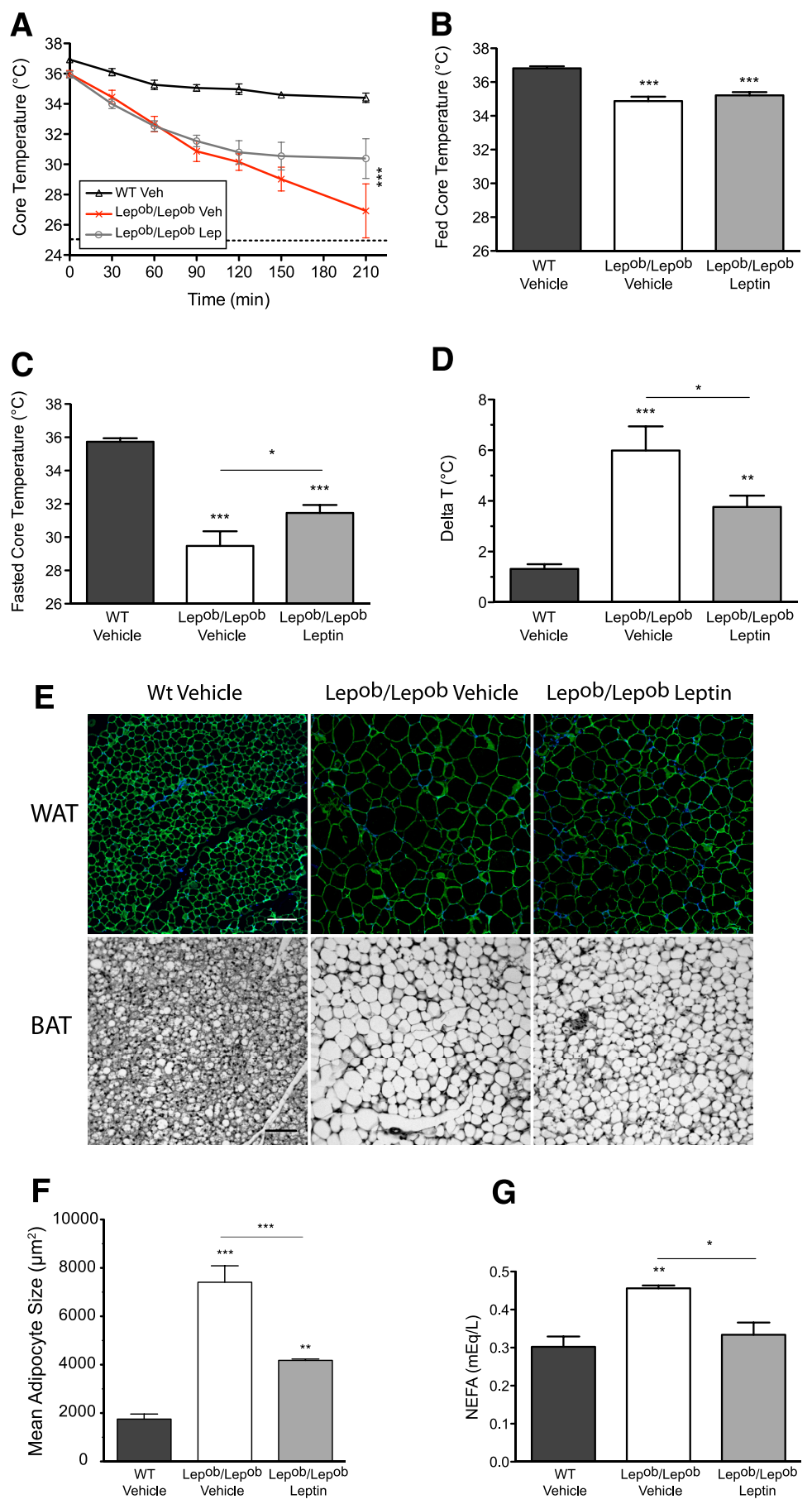

Figure 8. Postnatal leptin treatment improves the thermogenic response of leptin-deficient mice during a cold or a nutritional challenge. $A$, Core temperature during a $210 \mathrm{~min}$ cold challenge at $+4^{\circ} \mathrm{C}$ of 9 - to 10 -week-old WT Vehicle $(n=15)$, Lep ${ }^{\mathrm{ob}} /$ Lep $^{\mathrm{ob}}$ Vehicle $(n=8)$, and Lep ${ }^{\mathrm{ob}} /$ Lep $^{\mathrm{ob}}$ Leptin male mice $(n=12)$. $\boldsymbol{B}, \boldsymbol{C}$, Basal core body temperatures of ad libitum fed $(\boldsymbol{B})$ or $14 \mathrm{~h}$ fasting (C) WT Veh $(n=15)$, Lep ${ }^{\mathrm{ob}} /$ Lep ${ }^{\mathrm{ob}}$ Vehicle $(n=8)$, and Lep ${ }^{\mathrm{ob}} /$ Lep ${ }^{\mathrm{ob}}$ Leptin $(n=12)$ male mice at $8-10$ weeks. D, Basal core temperature difference (delta temperature) between fed and fasted states. $\boldsymbol{E}$, Representative confocal images of epididymal WAT labeled using an antisera against PerilipinA/B (top) and bright-field images of BAT stained with hematoxylin and eosin on paraffin-embedded sections (bottom) from 20-week-old WT Vehicle $(n=4)$, Lep ${ }^{\mathrm{ob}} /$ Lep $^{\mathrm{ob}}$ Vehicle $(n=4)$, and Lep ${ }^{\mathrm{ob}} /$ Lep $^{\mathrm{ob}}$ Leptin $(n=4)$ male mice. Scale bars: $50 \mu \mathrm{m}$ for WAT and $200 \mu \mathrm{m}$ for BAT. $\boldsymbol{F}$, Quantification of WAT cell surface area. G, Plasma levels of NEFA at 20 weeks. All data are mean \pm SEM. One-way or two-way ANOVA and pairwise post hoc tests were performed for each dependent variable. ${ }^{*} p<0.05,{ }^{* *} p<0.01$, and ${ }^{* * *} p<0.001$. In A, only the significance between vehicle- or leptin-treated Lep ${ }^{\mathrm{ob}} /$ Lep ${ }^{\mathrm{ab}}$ mice is represented.

examined the impact of leptin deficiency on the total number of leptin receptor expressing cells in the ARH of adult Lep ${ }^{\mathrm{ob}} / \mathrm{Lep}^{\mathrm{ob}}$ mice by evaluating numbers of GFP-labeled cells in the ARH of Lep $^{\text {ob }} /$ Lep $^{\text {ob }}$ mice crossed with LepR-CreRosa26 reporter mice. 
A
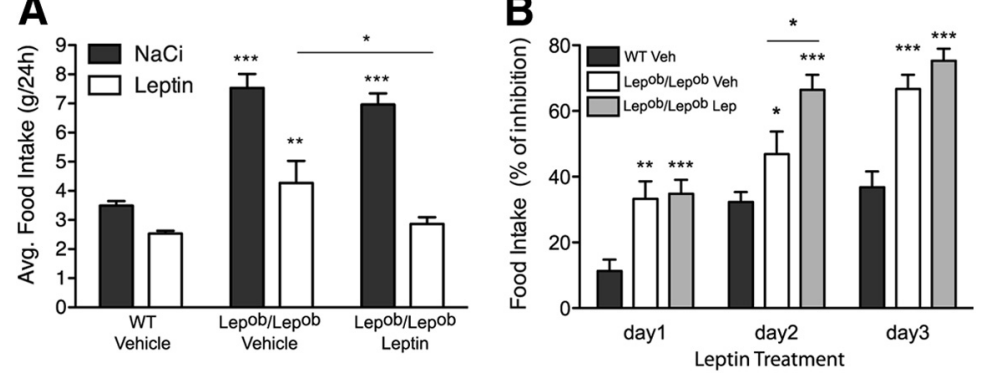

Figure 9. Postnatal leptin treatment increases in vivo leptin anorectic response in Lep ${ }^{\mathrm{ob}} /$ Lep $^{\mathrm{ob}}$ mice. In vivo leptin sensitivity in adult mice exposed to different neonatal leptin environments. Twelve-week-old mice ( $n=7-9$ mice per group) were injected intraperitoneally twice daily with Sodium Citrate (Vehicle) for $3 \mathrm{~d}$, then with leptin ( $2 \mathrm{mg} / \mathrm{kg}$ ) for $3 \mathrm{~d}$. Food intake was measured twice a day during the two injection periods. $\boldsymbol{A}$, Average $24 \mathrm{~h}$ food intake during injection periods. $\boldsymbol{B}$, Food intake following leptin treatment is represented as a percentage of inhibition versus control treatment. All data are mean $\pm \mathrm{SEM}$. Two-way ANOVA and pairwise post hoc test were performed for each dependent variable. ${ }^{*} p<0.05,{ }^{* *} p<0.01,{ }^{* *} p<0.001$.

In the ARH, the average number of LepR-GFP neurons per hemisection did not differ between WT-LepR-GFP mice (71.09 \pm $10.10, n=5)$ and Lep ${ }^{\text {ob }} /$ Lep $^{\text {ob }}$-LepR-GFP mice (84.33 \pm 6.818 , $n=4$ ) (data not shown), suggesting that the alterations in leptinsensitive pathways observed in Lep ${ }^{\mathrm{ob}} / \mathrm{Lep}^{\mathrm{ob}}$ mice are not likely to result from an impaired number of leptin-responsive cells in the ARH.

\section{Discussion}

To accomplish the sensory-motor integration necessary for homeostatic regulation, appropriate patterns of hypothalamic connectivity must be established during development linking neurons that respond to environmental signals with neurons that control hormone secretion from the pituitary or autonomic function. ARH neurons relay metabolic signals through projections established during postnatal development. Normal formation of these pathways requires the presence of leptin which promotes outgrowth of axons during a discrete postnatal critical period (Bouret et al., 2004a,b). Here, we found that postnatal leptin also specifies cellular targeting of ARH inputs within specific regional domains of preautonomic components of the PVH and exerts heterogeneous actions on targeting AgRP- and $\alpha \mathrm{MSH}$-containing projections to the PVH. These permanent effects of leptin on patterning of ARH projections to the PVH are associated with attenuated body weight gain, reduced food intake, and improved physiological responses to sympathetic stimuli in adult Lep ${ }^{\mathrm{ob}} /$ Lep $^{\mathrm{ob}}$ mice.

Densities of axon terminals and neuronal inputs to both neuroendocrine and preautonomic compartments are permanently reduced in $\mathrm{Lep}^{\mathrm{ob}} / \mathrm{Lep}^{\mathrm{ob}}$ mice, demonstrating that leptin exposure is necessary for normal development of ARH-derived projections to both of these functional domains of the PVH. Surprisingly, we did not observe significant restorative effects of neonatal leptin treatment on peptidergic innervation of NE neurons, suggesting a requirement for sustained leptin action on this circuit. However, it remains to be determined whether AgRP or $\alpha \mathrm{MSH}$ innervation of subpopulations of neuroendocrine neurons are uniquely impacted by leptin's developmental actions. For example, leptin may be required to specify normal densities of NPY/AgRP inputs onto TRH neurons, but not onto other cell types. It is equally likely that in addition to neonatal exposure, leptin may be required throughout adulthood to maintain peptidergic inputs onto NE neurons in the PVH in much the same way that sex steroid hormones are required in mature animals to maintain sexually dimorphic patterns of connectivity and physiological responses (Simerly, 2002; McCarthy et al., 2009).

The density of AgRP fibers was particularly high in parts of the PVH containing large numbers of preautonomic neurons, whereas POMC-derived fibers were sparsely distributed. AgRP innervation of PE neurons was dependent on postnatal leptin, similar to findings in NE compartments of the PVH. However, postnatal leptin treatment was sufficient to rescue AgRP fiber innervation densities onto preautonomic neurons to levels typical of WT mice. A surprising finding was that $\mathrm{POMC} / \alpha \mathrm{MSH}$ innervation onto preautonomic neurons appears to be relatively resistant to the developmental effects of leptin, since we observed neither a decrease in innervation of preautonomic neurons in Lep ${ }^{\mathrm{ob}} / \mathrm{Lep}^{\mathrm{ob}}$ mice, nor any detectable increase in the density of terminals onto preautonomic neurons in animals treated with exogenous leptin. This finding is consistent with an earlier observation that reactivation of melanocortin-4 receptor (MC4-R) in SIM-1-expressing neurons does not impact energy expenditure (Balthasar et al., 2005), while reactivation of melanocortin signaling in sympathetic motor neurons reduces body weight gain and improves the energy expenditure deficit typical of MC4-R-null mice (Rossi et al., 2011). One possible explanation for the target-specific effects of leptin on POMC innervation in the PVH is that NE and PA neurons may be innervated by different subpopulations of POMC neurons. This notion is in line with several observations that indicate heterogeneity of POMC neurons. The electrophysiological properties of POMC neurons in response to glucose, insulin and leptin are not uniform in the ARH (Ibrahim et al., 2003; Parton et al., 2007; Williams et al., 2010) and diversity in their neurotransmitter phenotype has also been reported (Hentges et al., 2009). In addition, a detailed characterization of NPY and POMC neuronal lineages revealed that a subpopulation of POMC precursors give rise to other mature cell types, including a subpopulation of NPY neurons (Padilla et al., 2010). Thus, both the cell type and target-specific sensitivity to the developmental actions of leptin may reflect differences in neurotrophic responses of each subpopulation of neurons that are directed toward specific neuronal targets in the PVH. Whether targetspecific differences in developmental sensitivity to leptin are due to cell type-specific signaling pathways coupled to leptin receptors, as was reported for the neurotrophic actions of leptin on NPY and POMC neurons (Bouret et al., 2012), remains to be determined.

In addition to regulatory effects conveyed by peptidergic projections from ARH to PVH, the activity of hypothalamic neurons is controlled by glutamatergic and GABAergic inputs. PVH neurons receive both glutamatergic and GABAergic innervation from the ARH with the majority of NPY/AgRP neurons containing GABA, while POMC neurons are primarily glutamatergic (Horvath et al., 1997; Collin et al., 2003). However, we did not observe a comparable degree of developmental plasticity in the density of either vGlut2- or VGAT-labeled inputs to NE or PA neurons. Moreover, ratios of these inputs to subpopulations of NE or PA neurons in the PVH appeared to be remarkably stable between WT and Lep ${ }^{\mathrm{ob}} / \mathrm{Lep}^{\mathrm{ob}}$ mice. It should be noted, however, 
that we do not know whether compensatory changes in synapse density may occur later in development, as has been observed in other brain regions, impacting circuit architecture and neuronal homeostasis (Cesa and Strata, 2009; Lu et al., 2009; Blankenship and Feller, 2010). Moreover, Pinto et al. (2004) demonstrated that treatment of adult Lep ${ }^{\mathrm{ob}} / \mathrm{Lep}^{\mathrm{ob}}$ mice with leptin rapidly alters the ratio of glutamatergic and GABAergic synapses onto NPY and POMC neurons in the ARH, suggesting that acute exposure to leptin may modulate the excitatory and inhibitory balance in mature animals. It is equally plausible that a majority of inputs to PVH neurons may arise from non-ARH and non-leptin-sensitive sources, thereby masking leptin's modulatory effect on a subset of excitatory or inhibitory inputs to ARH neurons. Anatomical studies show a dense population of GABAergic interneurons surrounding the PVH, which innervate PVH cells (Roland and Sawchenko, 1993) and could potentially compensate for loss of leptin-dependent excitatory or inhibitory inputs to NE or PA neurons. Alternatively, a recent gene-targeting study revealed that leptin mediates its anorectic action predominantly via a distributed network of presynaptic GABAergic neurons that collectively reduce inhibitory tone to POMC neurons (Vong et al., 2011). Thus, leptin may also act upstream of POMC neurons to specify patterns of connectivity that alter neuronal response properties of these important cells.

Variation in the timing and amplitude of the leptin surge increases susceptibility to obesity later in life (Yura et al., 2005; Delahaye et al., 2008). We observed a slight, but significant, decrease in body weight gain and food intake in adult Lep ${ }^{\mathrm{ob}} / \mathrm{Lep}^{\mathrm{ob}}$ mice treated postnatally with leptin, despite the magnitude of obesity conferred by the Lep ${ }^{\text {ob }} /$ Lep $^{\text {ob }}$ genotype. Furthermore, Lep $^{\text {ob }} /$ Lep $^{\text {ob }}$ mice treated postnatally with leptin exhibit enhanced responsiveness to exogenous leptin in adulthood, demonstrating that exposure to leptin during a discrete developmental window is sufficient to impact leptin sensitivity later in life. These observations are consistent with our structural findings that postnatal leptin treatment can rescue patterns of neuronal targeting in the PVH. The ability of postnatal leptin to restore targeting of peptidergic innervation to PA neurons in the $\mathrm{PVH}$ corresponds to the improved sympathetic responses observed in Lep $^{\text {ob }} /$ Lep $^{\text {ob }}$ mice when challenged in a cold environment, or by fasting. Furthermore, activation of neurons in the PVH inhibits BAT sympathetic nerve activity and BAT thermogenesis (Madden and Morrison, 2009). Therefore the improved innervation of PA neurons in the PVH may contribute to the improved thermogenic response observed in $\mathrm{Lep}^{\mathrm{ob}} / \mathrm{Lep}^{\mathrm{ob}}$ mice that received postnatal leptin. The DMH also represents a major target for leptin-dependent ARH projections (Bouret et al., 2004a) and growing evidence suggests involvement of the DMH in mediating the effects of melanocortins on energy expenditure and regulation of BAT thermogenesis (Enriori et al., 2011; Zhang et al., 2011). Whether a developmental action of postnatal leptin on $\mathrm{ARH}$ projections to the DMH is required to maintain normal control of energy expenditure remains to be established.

We currently know little about the molecular guidance cues that control development of hypothalamic circuits. Studies in extrahypothalamic neural systems have identified a variety of molecular mechanisms mediating circuit development, including competitive interactions between neighboring branch arbors, synapse-dependent branch stabilization (Gibson and Ma, 2011), as well as contact-mediated guidance cues (Kolodkin and TessierLavigne, 2010). Indeed, diffusible guidance molecules such as $\mathrm{Ne}$ trins, Slits, and Semaphorins are highly expressed in the PVH during development, with expression of their cognate receptors on ARH neurons (Bouret, 2010). Interestingly, in mice that are deficient in Contactin, a cell adhesion molecule involved in the formation of axonal projections, innervation of the PVH by AgRP and $\alpha \mathrm{MSH}$ axon terminals is significantly impaired (Fetissov et al., 2005). Regardless of the target molecules mediating cell type-specific patterns of innervation in the $\mathrm{PVH}$, the ability of leptin to specify patterns of neuronal connectivity during development may differentially impact distinct components of autonomic regulation, while imposing a requirement for sustained leptin action for accurate control of neuroendocrine responses. Unraveling the mechanisms through which leptin imprints patterns of connectivity in the hypothalamus during critical periods of development will enable a better understanding of how factors that alter postnatal leptin secretion impact the architecture of metabolic circuitry controlling energy homeostasis throughout life.

\section{References}

Balthasar N, Dalgaard LT, Lee CE, Yu J, Funahashi H, Williams T, Ferreira M, Tang V, McGovern RA, Kenny CD, Christiansen LM, Edelstein E, Choi B, Boss O, Aschkenasi C, Zhang CY, Mountjoy K, Kishi T, Elmquist JK, Lowell BB (2005) Divergence of melanocortin pathways in the control of food intake and energy expenditure. Cell 123:493-505. CrossRef Medline

Biag J, Huang Y, Gou L, Hintiryan H, Askarinam A, Hahn JD, Toga AW, Dong HW (2012) Cyto- and chemoarchitecture of the hypothalamic paraventricular nucleus in the C57BL/6J male mouse: a study of immunostaining and multiple fluorescent tract tracing. J Comp Neurol 520: 6-33. CrossRef Medline

Blankenship AG, Feller MB (2010) Mechanisms underlying spontaneous patterned activity in developing neural circuits. Nat Rev Neurosci 11: 18-29. CrossRef Medline

Bouret SG (2010) Development of hypothalamic neural networks controlling appetite. Forum Nutr 63:84-93. Medline

Bouret SG, Draper SJ, Simerly RB (2004a) Formation of projection pathways from the arcuate nucleus of the hypothalamus to hypothalamic regions implicated in the neural control of feeding behavior in mice. J Neurosci 24:2797-2805. CrossRef Medline

Bouret SG, Draper SJ, Simerly RB (2004b) Trophic action of leptin on hypothalamic neurons that regulate feeding. Science 304:108-110. CrossRef Medline

Bouret SG, Bates SH, Chen S, Myers MG Jr, Simerly RB (2012) Distinct roles for specific leptin receptor signals in the development of hypothalamic feeding circuits. J Neurosci 32:1244-1252. CrossRef Medline

Buettner C, Muse ED, Cheng A, Chen L, Scherer T, Pocai A, Su K, Cheng B, Li X, Harvey-White J, Schwartz GJ, Kunos G, Rossetti L, Buettner C (2008) Leptin controls adipose tissue lipogenesis via central, STAT3independent mechanisms. Nat Med 14:667-675. CrossRef Medline

Cesa R, Strata P (2009) Axonal competition in the synaptic wiring of the cerebellar cortex during development and in the mature cerebellum. Neuroscience 162:624-632. CrossRef Medline

Collin M, Bäckberg M, Ovesjö ML, Fisone G, Edwards RH, Fujiyama F, Meister B (2003) Plasma membrane and vesicular glutamate transporter mRNAs/proteins in hypothalamic neurons that regulate body weight. Eur J Neurosci 18:1265-1278. CrossRef Medline

Coppari R, Ichinose M, Lee CE, Pullen AE, Kenny CD, McGovern RA, Tang V, Liu SM, Ludwig T, Chua SC Jr, Lowell BB, Elmquist JK (2005) The hypothalamic arcuate nucleus: a key site for mediating leptin's effects on glucose homeostasis and locomotor activity. Cell Metab 1:63-72. CrossRef Medline

Cowley MA, Smart JL, Rubinstein M, Cerdán MG, Diano S, Horvath TL, Cone RD, Low MJ (2001) Leptin activates anorexigenic POMC neurons through a neural network in the arcuate nucleus. Nature 411:480-484. CrossRef Medline

Delahaye F, Breton C, Risold PY, Enache M, Dutriez-Casteloot I, Laborie C, Lesage J, Vieau D (2008) Maternal perinatal undernutrition drastically reduces postnatal leptin surge and affects the development of arcuate nucleus proopiomelanocortin neurons in neonatal male rat pups. Endocrinology 149:470-475. CrossRef Medline

Dong HW (2008) Allen reference atlas: a digital color brain atlas of the C57BL/6J male mouse. New York: Wiley. 
Elias CF, Lee C, Kelly J, Aschkenasi C, Ahima RS, Couceyro PR, Kuhar MJ, Saper CB, Elmquist JK (1998) Leptin activates hypothalamic CART neurons projecting to the spinal cord. Neuron 21:1375-1385. CrossRef Medline

Enriori PJ, Sinnayah P, Simonds SE, Garcia Rudaz C, Cowley MA (2011) Leptin action in the dorsomedial hypothalamus increases sympathetic tone to brown adipose tissue in spite of systemic leptin resistance. J Neurosci 31:12189-12197. CrossRef Medline

Fekete C, Légrádi G, Mihály E, Huang QH, Tatro JB, Rand WM, Emerson CH, Lechan RM (2000) alpha-Melanocyte-stimulating hormone is contained in nerve terminals innervating thyrotropin-releasing hormonesynthesizing neurons in the hypothalamic paraventricular nucleus and prevents fasting-induced suppression of prothyrotropin-releasing hormone gene expression. J Neurosci 20:1550-1558. Medline

Fetissov SO, Bergström U, Johansen JE, Hökfelt T, Schalling M, Ranscht B (2005) Alterations of arcuate nucleus neuropeptidergic development in contactin-deficient mice: comparison with anorexia and food-deprived mice. Eur J Neurosci 22:3217-3228. CrossRef Medline

Gibson DA, Ma L (2011) Developmental regulation of axon branching in the vertebrate nervous system. Development 138:183-195. CrossRef Medline

Hentges ST, Otero-Corchon V, Pennock RL, King CM, Low MJ (2009) Proopiomelanocortin expression in both GABA and glutamate neurons. J Neurosci 29:13684-13690. CrossRef Medline

Ho A, Chin A (1988) Circadian feeding and drinking patterns of genetically obese mice fed solid chow diet. Physiol Behav 43:651-656. CrossRef Medline

Horvath TL, Bechmann I, Naftolin F, Kalra SP, Leranth C (1997) Heterogeneity in the neuropeptide Y-containing neurons of the rat arcuate nucleus: GABAergic and non-GABAergic subpopulations. Brain Res 756: 283-286. CrossRef Medline

Ibrahim N, Bosch MA, Smart JL, Qiu J, Rubinstein M, Rønnekleiv OK, Low MJ, Kelly MJ (2003) Hypothalamic proopiomelanocortin neurons are glucose responsive and express K(ATP) channels. Endocrinology 144:1331-1340. CrossRef Medline

Kolodkin AL, Tessier-Lavigne M (2010) Mechanisms and molecules of neuronal wiring: a primer. Cold Spring Harb Perspect Biol 3(6) pii: a001727.

Lu B, Wang KH, Nose A (2009) Molecular mechanisms underlying neural circuit formation. Curr Opin Neurobiol 19:162-167. CrossRef Medline

Luiten PG, ter Horst GJ, Karst H, Steffens AB (1985) The course of paraventricular hypothalamic efferents to autonomic structures in medulla and spinal cord. Brain Res 329:374-378. CrossRef Medline

Madden CJ, Morrison SF (2009) Neurons in the paraventricular nucleus of the hypothalamus inhibit sympathetic outflow to brown adipose tissue. Am J Physiol Regul Integr Comp Physiol 296:R831-R843. CrossRef Medline

McCarthy M, De Vries G, Forger N (2009) Sexual differentiation of the brain: mode, mechanisms and meaning. Hormones Brain Behav 3:1707-1744.

Padilla SL, Carmody JS, Zeltser LM (2010) Pomc-expressing progenitors give rise to antagonistic neuronal populations in hypothalamic feeding circuits. Nat Med 16:403-405. CrossRef Medline
Parton LE, Ye CP, Coppari R, Enriori PJ, Choi B, Zhang CY, Xu C, Vianna CR, Balthasar N, Lee CE, Elmquist JK, Cowley MA, Lowell BB (2007) Glucose sensing by POMC neurons regulates glucose homeostasis and is impaired in obesity. Nature 449:228-232. CrossRef Medline

Persson S, Havton LA (2009) Retrogradely transported fluorogold accumulates in lysosomes of neurons and is detectable ultrastructurally using post-embedding immuno-gold methods. J Neurosci Methods 184:42-47. CrossRef Medline

Pinto S, Roseberry AG, Liu H, Diano S, Shanabrough M, Cai X, Friedman JM, Horvath TL (2004) Rapid rewiring of arcuate nucleus feeding circuits by leptin. Science 304:110-115. CrossRef Medline

Roland BL, Sawchenko PE (1993) Local origins of some GABAergic projections to the paraventricular and supraoptic nuclei of the hypothalamus in the rat. J Comp Neurol 332:123-143. CrossRef Medline

Rossi J, Balthasar N, Olson D, Scott M, Berglund E, Lee CE, Choi MJ, Lauzon D, Lowell BB, Elmquist JK (2011) Melanocortin-4 receptors expressed by cholinergic neurons regulate energy balance and glucose homeostasis. Cell Metab 13:195-204. CrossRef Medline

Schwartz MW, Woods SC, Porte D Jr, Seeley RJ, Baskin DG (2000) Central nervous system control of food intake. Nature 404:661-671. Medline

Simerly RB (2002) Wired for reproduction: organization and development of sexually dimorphic circuits in the mammalian forebrain. Annu Rev Neurosci 25:507-536. CrossRef Medline

Simerly RB (2008) Hypothalamic substrates of metabolic imprinting. Physiol Behav 94:79-89. CrossRef Medline

Swanson LW (2000) Cerebral hemisphere regulation of motivated behavior. Brain Res 886:113-164. CrossRef Medline

Swanson LW, Kuypers HG (1980) The paraventricular nucleus of the hypothalamus: cytoarchitectonic subdivisions and organization of projections to the pituitary, dorsal vagal complex, and spinal cord as demonstrated by retrograde fluorescence double-labeling methods. J Comp Neurol 194: 555-570. CrossRef Medline

van den Top M, Lee K, Whyment AD, Blanks AM, Spanswick D (2004) Orexigen-sensitive NPY/AgRP pacemaker neurons in the hypothalamic arcuate nucleus. Nat Neurosci 7:493-494. CrossRef Medline

Vong L, Ye C, Yang Z, Choi B, Chua S Jr, Lowell BB (2011) Leptin action on GABAergic neurons prevents obesity and reduces inhibitory tone to POMC neurons. Neuron 71:142-154. CrossRef Medline

Williams KW, Margatho LO, Lee CE, Choi M, Lee S, Scott MM, Elias CF, Elmquist JK (2010) Segregation of acute leptin and insulin effects in distinct populations of arcuate proopiomelanocortin neurons. J Neurosci 30:2472-2479. CrossRef Medline

Yura S, Itoh H, Sagawa N, Yamamoto H, Masuzaki H, Nakao K, Kawamura M, Takemura M, Kakui K, Ogawa Y, Fujii S (2005) Role of premature leptin surge in obesity resulting from intrauterine undernutrition. Cell Metab 1:371-378. CrossRef Medline

Zhang Y, Kerman IA, Laque A, Nguyen P, Faouzi M, Louis GW, Jones JC, Rhodes C, Münzberg H (2011) Leptin-receptor-expressing neurons in the dorsomedial hypothalamus and median preoptic area regulate sympathetic brown adipose tissue circuits. J Neurosci 31:1873-1884. CrossRef Medline 